\title{
Discrepancies in pain presentation caused by adverse psychosocial conditions as compared to pain due to high physical workload?
}

\author{
Inger Arvidsson*, Jenny Gremark Simonsen, Istvan Balogh, Gert-Åke Hansson, Camilla Dahlqvist, \\ Lothy Granqvist, Kerstina Ohlsson, Anna Axmon, Björn Karlson and Catarina Nordander \\ Department of Occupational and Environmental Medicine, University Hospital, SE-221 85 Lund, Sweden
}

\begin{abstract}
Disorders in the musculoskeletal system have been associated with a high physical workload as well as psychosocial and individual factors. It is however not obvious which of these factors that is most important to prevent. Musculoskeletal disorders in neck and upper extremity was assessed by interview and clinical examination in 79 teachers and 93 assisting nurses, all females. Psychosocial work environment was assessed by questionnaire. The physical workload was recorded by technical measurements of postures, movements and muscular load, in 9 teachers and 12 nurses. The physical workload was lower among the teachers, but they had a more demanding psychosocial work environment. Among the nurses, but not in the teachers, the neck-shoulder disorders were associated with a high body mass index (BMI). The teachers reported neck-shoulder complaints to a higher extent than the nurses, but had much lower prevalence of diagnoses in the clinical examination ( $12 \%$ vs. $25 \%$; POR 0.3 CI $0.1-1.2$; adjusted for age and BMI). The results suggest that adverse psychosocial conditions among the teachers give rise to a different kind of pain in the neck-shoulder region than from physical overload, troublesome but not as severe as the one afflicting the nurses.
\end{abstract}

Keywords: musculoskeletal disorders, clinical examination, technical measurements

\section{Introduction}

Disorders in the musculoskeletal system are the leading cause of occupational injuries. An increased risk has been associated with a high physical workload as well as a poor psychosocial work environment [1-3]. Further, individual factors may influence the incidence of disorders [4]. However, it is not obvious which of these factors that is the most important, and should be given priority to in preventing actions.

Assisting nurses have several well-known physical risk factors, such as awkward postures, lifting of patients and material handling [5-6]. Teachers, on the other hand, supposedly have a relatively low physical workload, but high psychosocial demands. The aim of this study was to assess the musculoskeletal health among teachers and assisting nurses, in relation to their physical and psychosocial working conditions, as well as individual factors.

\section{Methods}

\subsection{Study populations}

The study groups consisted of 79 female teachers working in elementary school [mean age 45 , range 26-65 years; mean body mass index (BMI) 23 , range 18 - 37] and 93 female operating-room assistant nurses (mean age 50, range 23-65 years; mean BMI 25 , range $17-39$ ).

\footnotetext{
*Corresponding author. E-mail: inger.arvidsson@med.lu.se
} 


\subsection{Methods}

All subjects were interviewed concerning complaints from neck, shoulders, elbows and hands, according to the Nordic Questionnaire [7], and about individual factors (BMI, smoking, physical activity). Thereafter, a standardised clinical examination [8-9], with predefined criteria for diagnosis, was performed in all subjects. The prevalences of reported complaints the last seven days and 'at least one diagnosis' was calculated for the neck-shoulders and elbowshands regions, respectively.

The psychosocial work environment was assessed by a written questionnaire, including the demandcontrol model by Karasek and Theorell [10], Copenhagen Psychosocial Questionnaire [11] and Maslach Burnout Inventory [12].

The physical workload was recorded by technical measurements in representative subgroups, twelve assistant nurses and nine teachers, during one workday/individual. Postures and movement velocities in the head, the upper back and the upper arms were measured by inclinometry [13]. The muscular activities ( $\%$ of maximal voluntary contraction; MVE) and time proportion of muscular rest $(<0.5 \% \mathrm{MVE})$ in the trapezius muscles were measured by electromyography [13].

\subsection{Statistics}

The Mann-Whitney U-test was used for evaluations of differences between the groups in physical workload and psychosocial measures. For differences between the groups in complaints and diagnoses, the prevalence odds ratios (POR) with 95\% confidence intervals (CI) were calculated, using logistic regression. Logistic regression was also used for associations (within the groups) between disorders and BMI, as well as between disorders and age. The SPSS statistical package (PASW Statistics 18) was used for all tests.

\section{Results}

\subsection{Physical workload}

As expected, the physical workload was lower in the teachers than in the nurses. The muscular load in the right trapezius muscle was lower [2.9 (SD 2.2) vs.
$5.1(\mathrm{SD} 2.0) \% \mathrm{MVE} ; 50^{\text {th }}$ percentile; $\left.\mathrm{p}=0.04\right]$, and the proportion of muscular rest ( $\%$ of time) was higher [20 (SD 11) \% vs. 9.7 (SD 9.4) \%; $\mathrm{p}=0.02]$. The movement velocity for the right upper arm was 17 (SD 3.2) $\%$ s for the teachers, as compared to 28 (SD 5.4) $\%$ in the nurses $(\mathrm{p}<0.001)$. The postures in the head and upper arms did not differ significantly between the groups.

\subsection{Psychosocial working conditions}

Concerning the psychosocial measures, the teachers reported statistically significantly higher demands than the nurses, in particular for the emotional demands [score 73 (SD 18) vs. 52 (SD 17), out of 100 possible; $\mathrm{p}<0.001]$. The nurses reported lower job control [score 2.8 (SD 0.3) vs. 3.2 (SD 0.3) in a 4-point scale; $p<0.001]$. Further, the teachers had a statistically significantly higher measure for burnout (2.9 vs. 2.2 in a 6-point scale; $\mathrm{p}<0.01$ ).

\subsection{Musculoskeletal disorders}

Though the physical workload was low among the teachers, their prevalence of reported complaints in the neck-shoulder region was numerically higher than in the nurses (Table 1). In contrast, the prevalence of 'at least one diagnosis' in the neckshoulder region was considerably lower in the teachers than in the nurses. Hence, the share of subjects who reported complaints but did not obtain any neck-shoulder diagnosis was significantly higher among the teachers as compared to the nurses [39\% vs. 20\%; POR 2.6; 95\% confidence interval (CI) 1.2 - 5.8]. In elbows-hands the pattern was different: the nurses had consistently higher prevalences of both complaints and diagnoses.

Among the nurses, neck-shoulder diagnoses was significantly associated with a high BMI (OR 1.15; CI $1.01-1.3$ ), while no such association was present among the teachers (OR 0.96; CI $0.8-1.2$ ). Age was not associated with neck-shoulder complaints or diagnoses in neither group. 
Table 1

Prevalences of complaints (the last seven days) and diagnoses in neck/shoulders and elbows/hands regions, respectively, among $79 *$ female teachers as compared to 93 assistant nurses. $\mathrm{POR}=$ Prevalence Odds Ratio, adjusted for age and body mass index $(\mathrm{BMI})$. CI=95\% confidence interval.

\begin{tabular}{llcr}
\hline Region & Prevalence (\%) & POR (CI), adjusted for age and \\
Measure & Teachers & Assistant nurses & $1.5(0.8-2.9)$ \\
\hline Neck/shoulders & 47 & 40 & $0.3(0.1-1.2)$ \\
Complaints & 12 & 25 & $0.4(0.2-0.8)$ \\
Diagnoses & & 37 & $0.3(0.1-1.2)$ \\
Elbows/hands & 16 & 13 & \\
Complaints & 3.8 & & \\
Diagnoses & & & \\
* One teacher did not participate in the clinical examination, only complaints data are available for her.
\end{tabular}

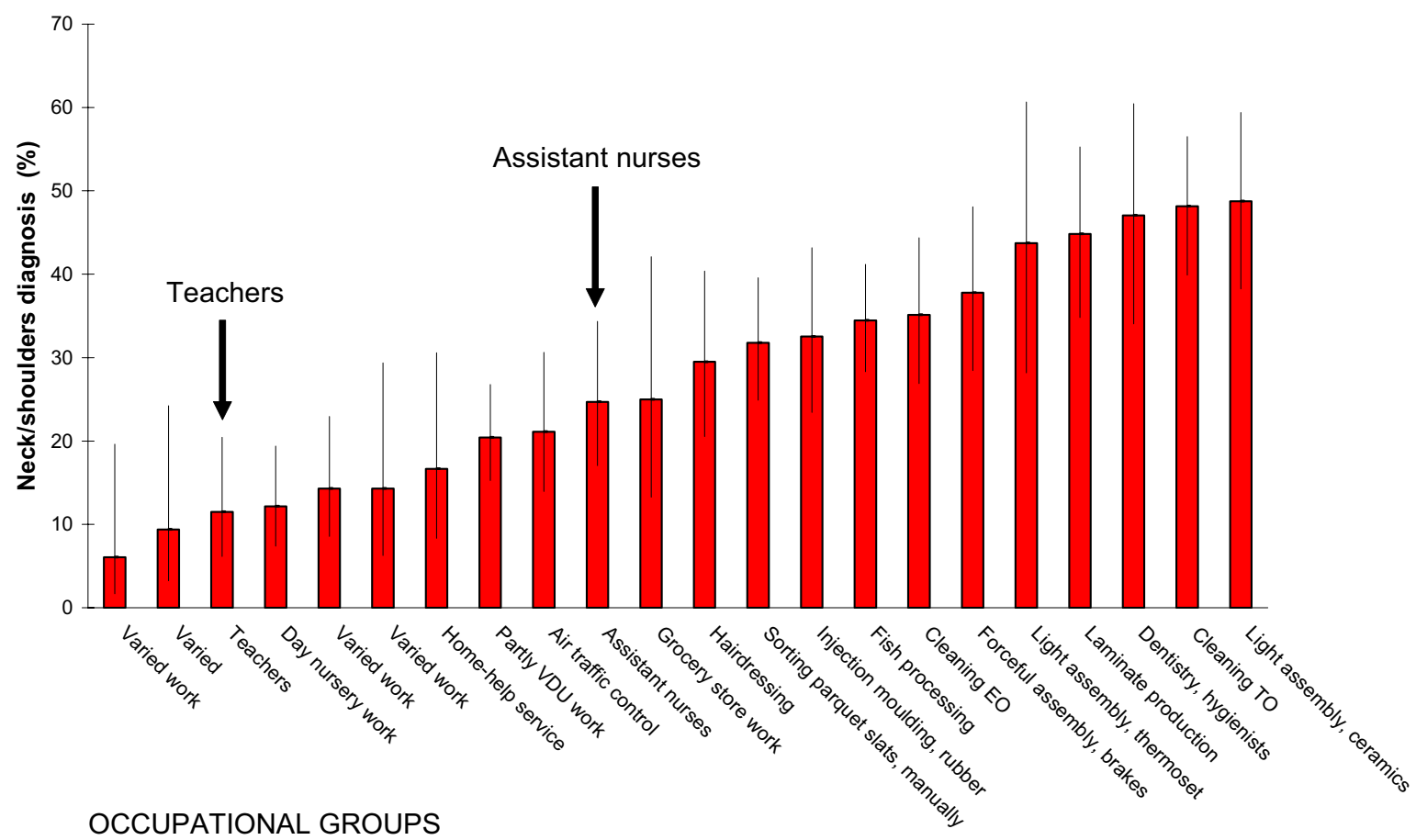

Figure. Prevalence of at least one neck-shoulder diagnosis among females in different occupational groups. The figure is modified from Nordander et al [9]. Arrows indicate the teachers and the assisting nurses. Thin bars indicate $95 \%$ confidence interval.

\section{Discussion}

The prevalence of neck-shoulder diagnoses was low among the teachers and medium high in the nurses, in comparison with females in twenty other occupational groups, all examined with the same method for clinical examinations (Figure; [9]). This was expected as the teachers showed a low physical workload. Surprisingly though, the teachers reported complaints from the neck-shoulder region to a higher extent than the nurses. Thus, only a minor share of the teachers reporting pain fulfilled the criteria for 
diagnosis in the clinical examination. As the teachers did not report more complaints from elbows-hands than the nurses, we do not believe that the former are more liable than the latter to report pain.

One plausible explanation to this discrepancy is that the teachers experienced worse psychosocial conditions and higher level of burnout, as compared to the nurses

BMI was higher among the nurses, and a high BMI was associated with neck-shoulder diagnoses among the nurses, but not in the teachers. However, the difference in prevalence of pain without diagnoses between the groups remained after adjustment for BMI.

The association between BMI and diagnoses might be due to a higher susceptibility to pain caused by physiological factors associated with a high BMI. However, since there was only an association between BMI and neck-shoulder diagnoses among nurses, not among the teachers, a more likely explanation is that a high physical workload among the former is aggravated by a high BMI.

In conclusion, the results suggest that adverse psychosocial conditions among the teachers give rise to a different kind of pain in the neck-shoulder region than from physical overload, troublesome but not as severe as the one afflicting the nurses.

\section{References}

[1] B.P. Bernard, Musculoskeletal disorders and workplace factors. A critical review of epidemiological evidence for work-related musculoskeletal disorders of the neck, upper extremity and low back. Cincinatti, OH, US: National Institute of Occupational Safety and Health; 1997.

[2] P.O. Östergren, B. Hansson, I. Balogh, A. Isacsson, P. Ørbæk, J. Winkel, et al., Incidence of shoulder and neck pain in a working population - effect modification between mechanical and psychosocial exposures at work. J Epidemiol Community Health 59 (2005), 721-728.
[3] U. Lundberg, Psychophysiology of work: stress, gender, endocrine response, and work-related upper extremity disorders. Am J Ind Med 41 (2002), 383-392.

[4] E. Viikari-Juntura, R. Martikainen, R. Luukkonen, P. Mutanen, E.P. Takala, H. Riihimaki, Longitudinal study on work related and individual risk factors affecting radiating neck pain. Occupational and environmental medicine 58 (2001), 345-352.

[5] A. Sheikhzadeh, C. Gore C, J.D. Zuckerman, M. Nordin, Perioperating nurses and technicians' perceptions of ergonomic risk factors in the surgical environment. Appl Ergon 40 (2009), 833-839.

[6] E. Bos, B. Krol, L. van der Star, J. Groothoff, Risk factors and musculoskeletal complaints in non-specialized nurses, IC nurses, operation room nurses, and X-ray technologists. Int Arch Occup Environ Health 80 (2007), 198-206.

[7] I. Kuorinka, B. Jonsson, Å. Kilbom, H. Vinterberg, G. Andersson, K. Jørgensen, K, Standardized Nordic questionnaires for the analysis of musculoskeletal symptoms. Applied Ergonomics 18 (1987), 233-237.

[8] K. Ohlsson, R.G. Attewell, B. Johnsson, A. Ahlm, S. Skerfving, An assessement of neck and upper extremity disorders by questionnaire and clinical examination. Ergonomics 37 81994), 891-897.

[9] C. Nordander, K. Ohlsson, I. Åkesson, I.Arvidsson I.Balogh, G.-Å. Hansson, U. Strömberg, R. Rittner, S. Skerfving, Risk of musculoskeletal disorders in neck and upper extremities, in groups of repetitive/constrained work. Ergonomics 52 (2009), 1226-1239.

[10] R. Karasek and T. Theorell, Healthy work. New York: Basic Books 1990.

[11] T.S. Kristensen, H. Hannerz, A. Høgh, V. Borg, The Copenhagen Psychosocial Questionnaire - a tool for the assessment and improvement of the psychosocial work environment. Scandinavian Journal of Work, Environment and Health 31(2005), 438-449.

[12] C. Maslach and S. Jackson, MBI Maslach Burnout Inventory ("Human Services Survey"). Research Edition. Manual. Palo Alto CA: Consulting Psychologists Press; 1981

[13] G.-Å. Hansson, I. Balogh, K. Ohlsson, L. Granqvist, C. Nordander, I. Arvidsson, I.Åkesson, J. Unge, R. Rittner, U. Strömberg, S. Skerfving, Physical workload in various types of work: Part II. Neck, shoulder and upper arm. Int. J. Ind. Ergon. 40 (2010), 267-281. 